\title{
Pulmonary and Urinary Clearance of Atrial Natriuretic Factor in Acute Congestive Heart Failure in Dogs
}

Mark A. Perrella, Kenneth B. Margulies, Chi-Ming Wei, Lawrence L. Aarhus, Denise M. Heublein, and John C. Burnett, Jr. Cardiorenal Research Laboratory, Departments of Internal Medicine and Physiology,

Mayo Clinic and Foundation, Rochester, Minnesota 55905

\begin{abstract}
Atrial natriuretic factor (ANF) is a peptide hormone of cardiac origin elevated in acute congestive heart failure (CHF), which is degraded by the enzyme neutral endopeptidase 24.11 (NEP). This study was designed to investigate the pulmonary and urinary clearance of ANF before and after the initiation of acute experimental CHF in dogs, and to assess the contribution of enzymatic degradation to these clearances in CHF. This study demonstrated a significant clearance of plasma ANF across the pulmonary circulation at baseline, and a tendency for pulmonary clearance to decrease in CHF (1115 \pm 268 to $498 \pm 173 \mathrm{ml} /$ min, NS). The pulmonary extraction of ANF present at baseline was not altered with acute CHF (36.0 \pm 7.8 to $34.9 \pm 12.1 \%$, NS). NEP inhibition (NEPI) abolished both the clearance and extraction of plasma ANF across the lung in CHF. Similarly, a significant urinary clearance of ANF was present at baseline, and in acute CHF the urinary clearance of ANF decreased $(0.14 \pm 0.02$ to $0.02 \pm 0.01 \mathrm{ml} / \mathrm{min}, P<0.05)$. NEPI prevented the decrease in the urinary clearance of $\mathrm{ANF}$, and enhanced the renal response to endogenous $A N F$, independent of further increases in plasma ANF during CHF. This study supports an important role for NEP in the pulmonary and urinary metabolism of endogenous ANF during acute CHF. (J. Clin. Invest. 1991.87:1649-1655.) Key words: atrial peptide • lung • kidney • metabolism
\end{abstract}

\section{Introduction}

Atrial natriuretic factor (ANF) ${ }^{1}$ is a peptide hormone of cardiac origin, which circulates as a 28 -amino acid peptide and contains a 17-member ring formed by a cysteine-cysteine disulfide bond. ANF is released in response to atrial stretch and participates in the physiologic regulation of sodium excretion, venous return, and the renin-angiotensin system (1-7). Al-

Address correspondence and reprint requests to Dr. Mark A. Perrella, Cardiorenal Research Laboratory, Mayo Clinic and Foundation, 200 First Street S.W., Rochester, MN 55905.

Received for publication 21 June 1990 and in revised form 12 December 1990.

1. Abbreviations used in this paper: $\mathrm{ANF}$, atrial natiuretic factor; $\mathrm{CHF}$, congestive heart failure; $\mathrm{CO}$, cardiac output; $\mathrm{FE}$, fractional excretion; GFC, gel filtration chromatography; GFR, glomerular filtration rate; cGMP, cyclic guanosine monophosphate; L, M, RAP, left, mean, right atrial pressure; NEPI, neutral endopeptidase inhibitor; $P$ or $U_{c l, e x}$, pulmonary or urinary clearance, extraction; RBF, renal blood flow; UV, urine flow.

The Journal of Clinical Investigation, Inc.

Volume 87, May 1991, 1649-1655 though congestive heart failure (CHF) is known to be associated with increases in circulating ANF (5), an understanding of ANF degradation in CHF is less clear. Binding of the peptide to biologically inactive clearance receptors (8), and degradation of the peptide via the enzyme system neutral endopeptidase 24.11 (NEP) (9-12), are two clearance mechanisms for ANF.

Berg and colleagues have reported that ANF is rapidly degraded by the kidney, in part via a nonsaturable NEP localized to the luminal membrane of the proximal tubule (9) Berg et al. Although the kidney has been accepted as a major site of ANF clearance $(9,10,11,13,14,15)$, studies conflict with regard to the existence of pulmonary clearance of ANF (16-19). Hollister and colleagues have proposed a significant contribution of the lung to ANF clearance (20), which is relevant to recent studies which have demonstrated significant NEP activity in the lung (21). While these studies support a role for the lung and kidney in the clearance of ANF via NEP, the pulmonary and urinary clearance of ANF in vivo remains unclear. Moreover, the pulmonary and urinary ANF clearance in CHF, a state characterized by marked increases in circulating ANF, also has not been investigated.

Therefore, the objective of this study was to determine the pulmonary and urinary clearance of ANF before and after the initiation of acute experimental CHF. A second objective of the study was to assess the contribution of enzymatic degradation of the atrial peptide to the urinary and pulmonary clearance of ANF in CHF by using a specific inhibitor of neutral endopeptidase 24.11 (NEPI) $(22,23)$. A third objective of these investigations was to define the cardiovascular and renal effects of NEPI in the presence of acute CHF.

\section{Methods}

Surgical preparation. Experiments were conducted in two groups of anesthetized dogs ( $n=6$ per group) weighing $19-24 \mathrm{~kg}$, with experimental acute CHF induced by rapid right ventricular pacing. This model is characterized by alterations in cardiorenal function and circulating hormones as observed in humans with acute biventricular heart failure $(4,23,24)$.

The dogs were fasted overnight $16 \mathrm{~h}$ before the acute experiment and allowed to drink water ad libitum until the time of the experiment. Dogs were anesthetized with sodium pentobarbital $(30 \mathrm{mg} / \mathrm{kg}$ i.v. $)$, and supplemental doses were given as necessary to maintain anesthesia. The dogs were then intubated and artificially ventilated (Harvard respirator; Harvard apparatus, Millis, MA) with supplemental oxygen at 4 liters per minute.

Surgical preparation in the acute experiment was as follows: the right external jugular vein was cannulated with a flow-directed, balloon-tipped, thermodilution catheter (model 93A-131-7F; American Edwards Laboratory, Anasco, Puerto Rico) and advanced into the pulmonary artery for measurement of cardiac filling pressures, determination of cardiac output, and pulmonary artery sampling. The heart was exposed via a left thoracotomy incision at the fourth intercostal space, 
the pericardium was opened, and an epicardial pacemaker lead was placed on the right ventricle to induce CHF. The left lung was retracted and a minor pulmonary vein cannulated for indirect monitoring of left atrial pressure and pulmonary vein sampling. The right femoral artery was cannulated for measurement of arterial pressure and sampling of arterial blood, and femoral veins were cannulated for infusion of inulin, NEPI, or supplemental anesthesia. The left kidney was exposed via a flank incision and the ureter cannulated for timed urine collections. An electromagnetic flow probe (Carolina Medical Electronics, King, $\mathrm{NC}$ ) was placed on the left renal artery for on-line monitoring of renal blood flow.

Experimental protocol. Upon completion of the surgical preparation, an inulin and saline solution was infused via a femoral vein catheter at $1 \mathrm{ml} / \mathrm{min}$ to achieve a plasma concentration of $\sim 50 \mathrm{mg} / \mathrm{dl}$. The dogs were then allowed to stabilize for $60 \mathrm{~min}$ without intervention. At the end of the equilibration period, one 30-min baseline clearance was obtained. Each clearance period consisted of a 30-min urine collection, measurement of hemodynamic parameters (midpoint of each clearance period), and withdrawal of $25 \mathrm{cc}$ of arterial blood for hormone analysis and electrolyte determination.

After the surgical preparation, equilibrium period, and a baseline 30-min clearance, rapid right ventricular pacing was initiated for $3 \mathrm{~h}$ to induce acute $\mathrm{CHF}$ (the pacing rate was adjusted to induce a $15 \%$ drop in mean arterial pressure). This model has previously been used in our laboratory $(24,25)$. After the first $30 \mathrm{~min}$ of pacing to allow for adjustments in pacing rate according to the hemodynamic parameters, the vehicle or NEPI was initiated in the groups. The remainder of the protocol differed among the two experimental groups. Group I: intravenous bolus infusion of a vehicle $(0.84 \%$ bicarbonate solution) given over $5 \mathrm{~min}$, followed by clearances every $30 \mathrm{~min}$ throughout the $3 \mathrm{~h}$ of acute pacing to serve as a control group. Group II: intravenous bolus infusion of the neutral endopeptidase inhibitor (SQ 28,603), $60 \mathrm{mg} / \mathrm{kg}$, dissolved in the above vehicle, and given over $5 \mathrm{~min}$, followed by clearances every $30 \mathrm{~min}$ throughout the $3 \mathrm{~h}$ of acute pacing. SQ 28,603 ( $N$-[2-(mercaptomethyl)-1-oxo-3-phenylpropyl]- $\beta$-alanine) isa competitive inhibitor of neutral endopeptidase 24.11 , selective in action with only weak activity against other renal brush border peptidases, such as angiotensin converting enzyme and aminopeptidase $M$ (Delaney, N. G., unpublished data). Additional blood samples were obtained simultaneously from the pulmonary artery and pulmonary vein catheters at baseline and $60 \mathrm{~min}$ after NEPI or vehicle infusion for determination of the pulmonary extraction and clearance of ANF.

Analyses. Blood for plasma sodium and inulin measurement was placed in heparinized tubes on ice, centrifuged at $2,500 \mathrm{rpm}$ and $3^{\circ} \mathrm{C}$, and refrigerated pending analysis. Plasma and urinary sodium concentrations were measured using ion-selective electrodes (Beckman Instruments, Brea, LA). Plasma and urinary inulin concentrations were determined by the anthrone method (25). Blood for hormone assay was placed in EDTA tubes and immediately placed on ice, after centrifugation at $2,500 \mathrm{rpm}$ and $3^{\circ} \mathrm{C}$, the plasma was decanted and stored at $-20^{\circ} \mathrm{C}$ until analysis. Urine was collected on ice and stored at $-20^{\circ} \mathrm{C}$ until analysis. The urine undergoing analysis for CGMP was heated to $>90^{\circ} \mathrm{C}$ before storage. Plasma and urinary ANF and cyclic guanosine monophosphate (cGMP) were measured by a specific RIA, as previously described $(5,26,27)$. The RIA technique used in this study was tested and revealed no interference with the urinary immunoassay for ANF in dogs receiving NEPI. The urine was also analyzed with a gel filtration P-6 column to assess the molecular form of ANF in the urine. Concentrations of immunoreactive ANF-separated fractions were then determined by RIA to $\alpha$-ANF (28). Glomerular filtration rate (GFR) was determined by inulin clearance. Hemodynamic data included mean arterial pressure (MAP), right atrial pressure (RAP), pulmonary vein pressure to assess left atrial pressure (LAP), renal blood flow (RBF), and cardiac output (CO). CO was measured by thermodilution technique and determined via the average of four measurements. Calculated parameters included: (a) urinary clearance of ANF ([urine flow $X$ urine concentration]/plasma concentration); $(b)$ pulmonary clearance of ANF ([pulmonary artery concentration - pulmonary vein concentration/pulmonary artery concentration] $\times \mathrm{CO})$; $(c)$ pulmonary extraction of ANF ([pulmonary artery concentration - pulmonary vein concentration/pulmonary artery concentration] $\times 100)$; and $(d)$ systemic vascular resistance ([MAP - RAP]/CO).

Statistics. For each experimental group, data from all clearance periods was measured and expressed as mean \pm SEM. All data was assessed by Student's paired $t$ tests for comparisons of absolute changes within each group. One sample hypothesis testing was used to determine the existence of the pulmonary and urinary clearance of ANF at baseline. Statistical significance was accepted for $P<0.05$.

\section{Results}

The cardiovascular, renal, and endocrine data for the two experimental groups are summarized in Tables I, II, and III. At baseline, in the presence of physiologic concentrations of plasma ANF, there was significant pulmonary extraction $\left(P_{E X} A N F\right)$ and clearance $\left(P_{\mathrm{CL}} \mathrm{ANF}\right)$ of $\mathrm{ANF}$ in both groups $(P<0.05)$.

Table I. Cardiovascular Hemodynamics before and after the Onset of Acute CHF, in the Presence and Absence of NEPI

\begin{tabular}{|c|c|c|c|c|}
\hline & \multirow[b]{2}{*}{ Baseline } & \multicolumn{3}{|c|}{ Acute heart failure } \\
\hline & & Prevehicle/NEPI & Postvehicle/NEPI & Vehicle/NEPI recovery \\
\hline \multicolumn{5}{|l|}{ Group I (vehicle) } \\
\hline MAP (mmHg) & $123 \pm 4$ & $101 \pm 4^{*}$ & $100 \pm 4^{*}$ & $105 \pm 10$ \\
\hline CO (liter/min) & $3.0 \pm 0.3$ & $1.9 \pm 0.2^{*}$ & $1.7 \pm 0.2^{* \S}$ & $1.3 \pm 0.2 * \S$ \\
\hline RAP (mmHg) & $1.0 \pm 0.3$ & $2.5 \pm 0.7^{*}$ & $2.8 \pm 0.8$ & $2.4 \pm 0.8$ \\
\hline LAP (mmHg) & $3.4 \pm 0.7$ & $14.3 \pm 1.0^{*}$ & $15.1 \pm 1.7^{*}$ & $13.8 \pm 23^{*}$ \\
\hline SVR (mmHg/liter/min) & $41.7 \pm 3.1$ & $53.6 \pm 3.8^{*}$ & $59.8 \pm 4.7^{* \S}$ & $84.7 \pm 6.5^{* 51}$ \\
\hline \multicolumn{5}{|c|}{ Group II (NEPI, 60 mg/kg i.v.) } \\
\hline MAP (mmHg) & $108 \pm 5$ & $89 \pm 4^{*}$ & $91 \pm 5^{*}$ & $75 \pm 4^{* 1}$ \\
\hline CO (liter/min) & $2.7 \pm 0.3$ & $1.6 \pm 0.2^{*}$ & $1.7 \pm 0.2^{*}$ & $1.0 \pm 0.1^{* 81}$ \\
\hline RAP (mmHg) & $1.7 \pm 0.8$ & $3.8 \pm 1.1$ & $3.3 \pm 1.1^{\S}$ & $2.5 \pm 1.2$ \\
\hline LAP (mmHg) & $3.2 \pm 0.5$ & $13.7 \pm 1.0^{*}$ & $12.4 \pm 0.8 *$ & $9.3 \pm 1.1 * 8$ \\
\hline
\end{tabular}

Data expressed as mean \pm SEM, $n=6 .{ }^{*} P<0.05$ vs. baseline, ${ }^{\S} P<0.05$ vs. prevehicle/NEPI, ${ }^{\prime} P<0.05$ vs. postvehicle/NEPI. 
Table II. Renal Hemodynamic and Excretory Function before and after the Onset of Acute CHF, in the Presence and Absence of NEPI

\begin{tabular}{|c|c|c|c|c|}
\hline & \multirow[b]{2}{*}{ Baseline } & \multicolumn{3}{|c|}{ Acute heart failure } \\
\hline & & Prevehicle/NEPI & Postvehicle/NEPI & Vehicle/NEPI recovery \\
\hline \multicolumn{5}{|l|}{ Group I (vehicle) } \\
\hline GFR (ml/min) & $29.3 \pm 3.4$ & $28.6 \pm 4.1$ & $28.7 \pm 4.3$ & $26.8 \pm 4.4$ \\
\hline $\mathrm{RBF}(\mathrm{ml} / \mathrm{min})$ & $207 \pm 36$ & $168 \pm 32$ & $157 \pm 27$ & $127 \pm 41$ \\
\hline $\mathrm{U} \mathrm{V}(\mathrm{ml} / \mathrm{min})$ & $0.23 \pm 0.08$ & $0.20 \pm 0.06$ & $0.14 \pm 0.02$ & $0.08 \pm 0.02$ \\
\hline $\mathrm{U} \mathrm{Na} V(\mu \mathrm{Eq} / \mathrm{min})$ & $41.9 \pm 18.6$ & $30.5 \pm 12.5$ & $15.9 \pm 5.0$ & $8.0 \pm 3.2$ \\
\hline $\mathrm{FE} \mathrm{Na}(\%)$ & $0.95 \pm 0.41$ & $0.85 \pm 0.43$ & $0.42 \pm 0.15$ & $0.21 \pm 0.07$ \\
\hline \multicolumn{5}{|c|}{ Group II (NEPI, $60 \mathrm{mg} / \mathrm{kg}$ i.v.) } \\
\hline GFR (ml/min) & $31.8 \pm 3.5$ & $24.1 \pm 2.0$ & $29.1 \pm 2.7^{\S}$ & $15.2 \pm 2.2^{* 51}$ \\
\hline $\mathrm{RBF}(\mathrm{ml} / \mathrm{min})$ & $189 \pm 24$ & $138 \pm 23^{*}$ & $130 \pm 22^{*}$ & $75 \pm 10^{* 51}$ \\
\hline $\mathrm{U} \mathrm{V}(\mathrm{ml} / \mathrm{min})$ & $0.19 \pm 0.03$ & $0.13 \pm 0.03^{*}$ & $0.41 \pm 0.08^{* \S}$ & $0.06 \pm 0.01^{* 1}$ \\
\hline $\mathrm{U} \mathrm{Na} \mathrm{V}(\mu \mathrm{Eq} / \mathrm{min})$ & $36.0 \pm 5.6$ & $17.7 \pm 5.3^{*}$ & $50.8 \pm 11.6^{5}$ & $10.3 \pm 3.4^{* 1}$ \\
\hline $\mathrm{FE} \mathrm{Na}(\%)$ & $0.84 \pm 0.15$ & $0.53 \pm 0.13$ & $1.32 \pm 0.32^{\S}$ & $0.46 \pm 0.14^{\prime}$ \\
\hline
\end{tabular}

Data expressed as mean $\pm \mathrm{SEM}, n=6{ }^{*} P<0.05$ vs. baseline, ${ }^{\S} P<0.05$ vs. prevehicle/NEPI, ${ }^{\top} P<0.05$ vs. postvehicle/NEPI.

Urinary clearance of $\mathrm{ANF}\left(\mathrm{U}_{\mathrm{CL}} \mathrm{ANF}\right)$ was also present in both groups $(P<0.05)$ at baseline.

Vehicle group. In the vehicle group (group 1), the initiation of $\mathrm{CHF}$ was associated with significant systemic hemodynamic changes including decreases in MAP and $\mathrm{CO}$, and increases in atrial pressures and systemic vascular resistance (SVR). As expected, marked increases in plasma ANF were observed in acute CHF (Fig. 1) and were associated with significant increases in plasma cGMP concentrations. As plasma ANF increased in acute $\mathrm{CHF}, \mathrm{U}_{\mathrm{CL}} \mathrm{ANF}$ tended to decrease. Although these changes did not achieve statistical significance initially, as $\mathrm{CHF}$ continued, $\mathrm{U}_{\mathrm{CL}} \mathrm{ANF}$ remained significantly decreased below baseline levels (Fig. 3). Associated with the decrease in $\mathrm{U}_{\mathrm{CL}} \mathrm{ANF}$, there was no change in GFR, urine flow, or urinary sodium excretion. $\mathrm{P}_{\mathrm{EX}} \mathrm{ANF}$ did not change with the onset of $\mathrm{CHF}$ in the vehicle group (Fig. $2 a$ ). The $\mathrm{P}_{\mathrm{CL}} \mathrm{ANF}$ tended to decrease in this group in association with decreases in cardiac output, however this $\mathbf{P}_{\mathrm{CL}}$ ANF decrease did not reach statistical significance (Fig. 2 b).

NEPI group. In group 2, in the presence of NEPI and acute $\mathrm{CHF}$, no decrease in $\mathrm{U}_{\mathrm{CL}} \mathrm{ANF}$ was observed, and $\mathrm{U}_{\mathrm{CL}} \mathrm{ANF}$ actually tended to increase (Fig. 3). The absolute changes in plasma and urine ANF concentrations are compared between the two groups in Fig. 4. Fractional excretion of ANF (FE ANF), a marker of renal tubular handling of filtered peptide, followed a similar pattern suggesting decreased tubular degradation of ANF in the presence of NEPI. Analysis of the urine with gel filtration chromatography (28) reveals the major molecular form of ANF in the urine after NEPI to be $\alpha$-ANF (Fig. 5). Regarding the pulmonary handling of $\mathrm{ANF}, \mathrm{P}_{\mathrm{EX}} \mathrm{ANF}$ and $P_{C L}$ ANF were abolished in the presence of NEPI (Fig. 2, $a$ and b). In acute CHF, after NEPI administration, circulating plasma ANF levels did not increase further (Fig. 1), although plasma cGMP did continue to increase.

Table III. Circulating Plasma and Renal Excretory Response of ANF and cGMP before and after the Onset of Acute CHF, in the Presence and Absence of NEPI

\begin{tabular}{|c|c|c|c|c|}
\hline & \multirow[b]{2}{*}{ Baseline } & \multicolumn{3}{|c|}{ Acute heart failure } \\
\hline & & Prevehicle/NEPI & Postvehicle/NEPI & Vehicle/NEPI recovery \\
\hline \multicolumn{5}{|l|}{ Group I (vehicle) } \\
\hline PL ANF (pg/ml) & $57 \pm 11$ & $383 \pm 84^{*}$ & $418 \pm 61^{*}$ & $343 \pm 103^{*}$ \\
\hline FE ANF (\%) & $0.55 \pm 0.15$ & $0.21 \pm 0.16$ & $0.07 \pm 0.02^{*}$ & $0.02 \pm 0.01^{*}$ \\
\hline PL cGMP (pmol/ml) & $2.5 \pm 0.3$ & $7.8 \pm 2.2^{*}$ & $8.7 \pm 1.9^{*}$ & $4.1 \pm 0.9^{1}$ \\
\hline U cGMP V (pmol/min) & $1095 \pm 175$ & $943 \pm 396$ & $1522 \pm 512$ & $1264 \pm 420$ \\
\hline U CL cGMP (ml/min) & $516 \pm 170$ & $229 \pm 120^{*}$ & $184 \pm 68$ & $416 \pm 249$ \\
\hline \multicolumn{5}{|c|}{ Group II (NEPI, $60 \mathrm{mg} / \mathrm{kg}$ i.v.) } \\
\hline PL ANF (pg/ml) & $39 \pm 6$ & $455 \pm 95^{*}$ & $457 \pm 58^{*}$ & $300 \pm 104^{* \varsigma}$ \\
\hline FE ANF (\%) & $0.33 \pm 0.13$ & $0.03 \pm 0.004$ & $0.72 \pm 0.38$ & $0.79 \pm 0.13^{* 5}$ \\
\hline PL cGMP (pmol/ml) & $2.6 \pm 0.2$ & $9.2 \pm 2.3^{*}$ & $12.9 \pm 2.7^{* 5}$ & $8.4 \pm 1.2^{*}$ \\
\hline U cGMP V (pmol/min) & $436 \pm 102$ & $602 \pm 158$ & $2323 \pm 535^{* \S}$ & $1262 \pm 283^{*}$ \\
\hline U CL cGMP (ml/min) & $172 \pm 36$ & $70 \pm 12^{*}$ & $200 \pm 47^{\S}$ & $166 \pm 39$ \\
\hline
\end{tabular}

Data expressed as mean \pm SEM, $n=6$, except group I, U cGMP V and U CL cGMP $(n=5)$, and group II, FE ANF $(n=5)$. ${ }^{*} P<0.05$ vs. baseline, ${ }^{8} P<0.05$ vs. prevehicle/NEPI, ${ }^{1} P<0.05$ vs. postvehicle/NEPI. 


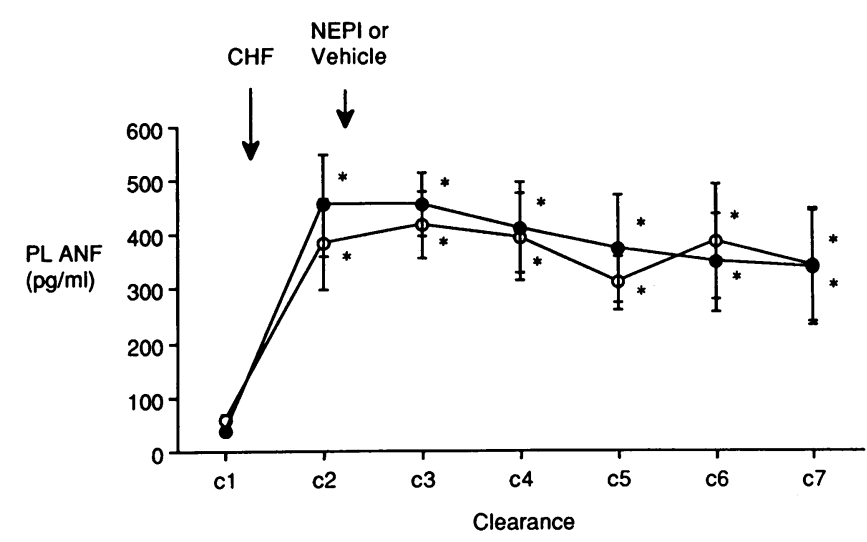

Figure 1. Plasma atrial natriuretic factor. PL ANF levels before and after the onset of acute CHF, in the presence of NEPI $(60 \mathrm{mg} / \mathrm{kg}$ i.v. $)$ $(n=6)(-\bullet-)$ or vehicle $(0.84 \%$ bicarbonate solution) $(n=6)$ $(-\circ-)$. The clearances represent 30 -min periods: $c l$, baseline; $c 2$, prevehicle/NEPI; $c 3$, postvehicle/NEPI; and $c 7$, recovery. ${ }^{*} P<0.05$ vs. cl.

NEPI administration in acute CHF decreased RAP, which continued to decrease during recovery. Similarly, LAP tended to decrease after NEPI and this decrease achieved significance during recovery. In addition, $\mathrm{CO}$ was initially maintained following NEPI, although during recovery, $\mathrm{CO}$ decreased substantially in association with a significant decrease in MAP and cardiac filling pressures.

Significant changes in renal excretory function, including
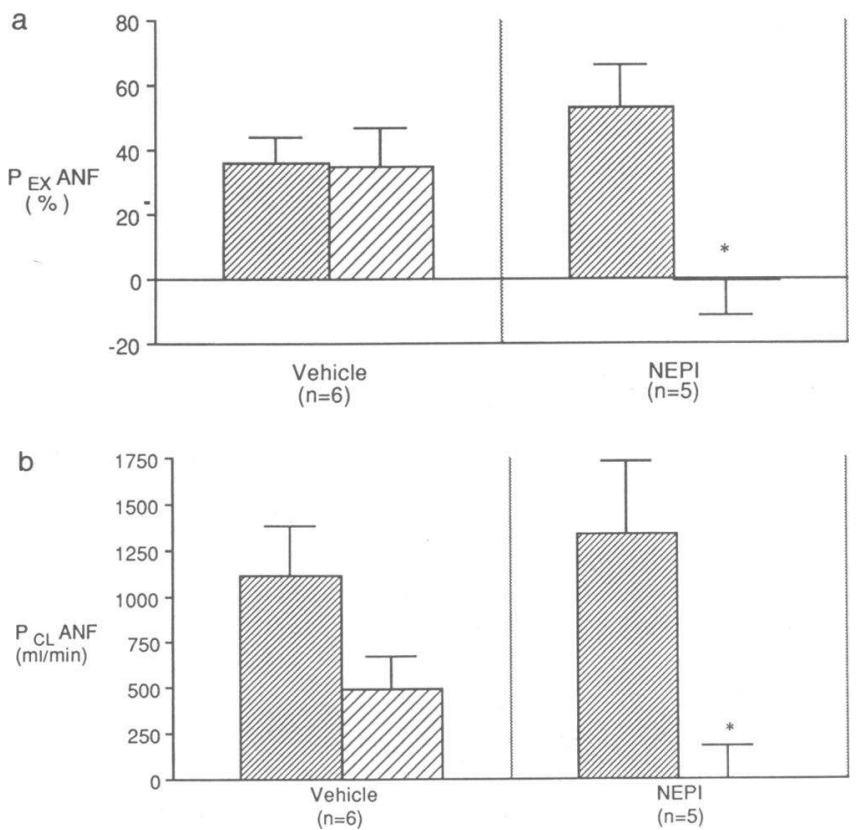

Figure 2. (a) Pulmonary extraction of atrial natriuretic factor. $P_{E x A N F}$ before and after the onset of acute CHF ( $\square$ ), in the presence of NEPI $\left(60 \mathrm{mg} / \mathrm{kg}\right.$ i.v.) or vehicle $\left(0.84 \%\right.$ bicarbonate solution). ${ }^{*} P$ $<0.05$ vs. baseline ( $($ ) ). (b) Pulmonary clearance of atrial natriuretic factor. $P_{C L} A N F$ before and after the onset of acute CHF ( $\square$ ), in the presence of an inhibitor to neutral endopeptidase 24.11 (NEPI, 60 $\mathrm{mg} / \mathrm{kg}$ i.v. $)$ or vehicle $\left(0.84 \%\right.$ bicarbonate solution). ${ }^{*} P<0.05$ vs. baseline (四).

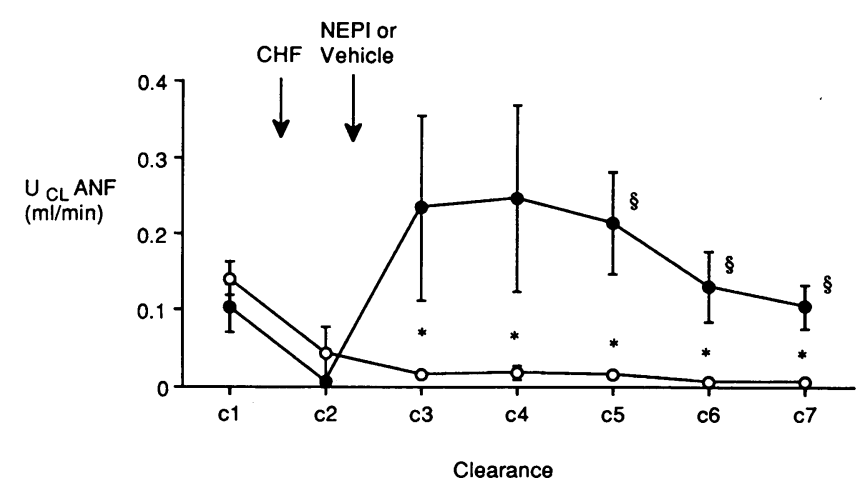

Figure 3. Urinary clearance of atrial natriuretic factor. $\mathrm{U}_{\mathrm{CL}} \mathrm{ANF}$ before and after the onset of acute CHF, in the presence of NEPI ( 60 $\mathrm{mg} / \mathrm{kg}$ i.v. $)(n=5)(-\bullet-)$ vehicle $(0.84 \%$ bicarbonate solution) $(n$ $=6)(-\circ-)$. The clearances represent 30 min periods: $c l$, baseline; $c 2$, prevehicle/NEPI; $c 3$, postvehicle/NEPI; and $c 7$, recovery. ${ }^{*} P$ $<0.05$ vs. $\mathrm{cl}, \S P<0.05$ vs. c2.

increases in GFR, urine flow (UV), absolute sodium excretion $\left(\mathrm{U}_{\mathrm{Na}} \mathrm{V}\right)$, and fractional excretion of sodium (FENa), were observed following NEPI in acute CHF. These renal actions of NEPI were accompanied by marked increases in both absolute urinary excretion of cGMP $\left(\mathrm{U}_{\mathrm{cGMP}} \mathrm{V}\right)$ and urinary clearance of cGMP $\left(\mathrm{U}_{\mathrm{CL}} \mathrm{cGMP}\right)$. During recovery in the NEPI Group, significant decreases in both renal hemodynamic and excretory parameters were observed in association with the decreases in arterial pressure described above.

\section{Discussion}

This study demonstrates for the first time the pulmonary and urinary clearance of ANF in acute CHF. A significant clearance of plasma ANF occurred across the pulmonary circulation under normal physiologic conditions. Although the $P_{C L} A N F$ tended to decrease during acute CHF, the $P_{E x} A N F$ was not altered. The administration of NEPI during acute CHF abolished both the clearance and extraction of plasma ANF
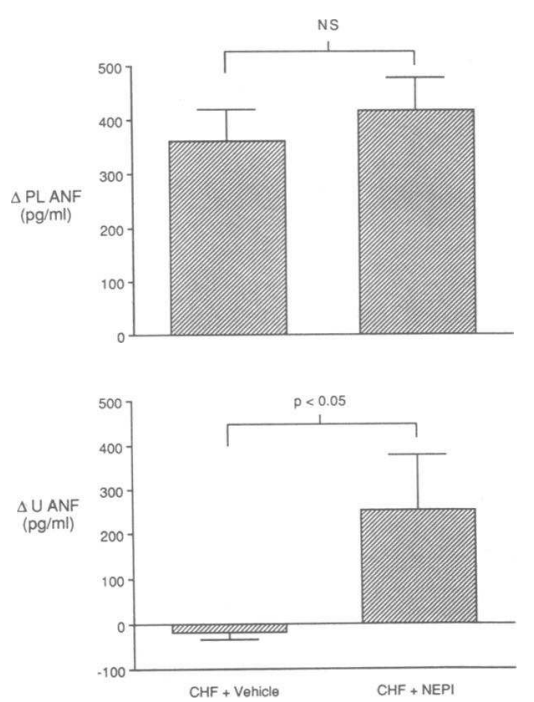

Figure 4. Alteration in plasma and urinary atrial natriuretic factor in congestive heart failure. Absolute changes in plasma (PL ANF) and urinary (UANF) ANF after the onset of acute CHF in the presence of NEPI $(60 \mathrm{mg} / \mathrm{kg}$ i.v. $)$ or vehicle $(0.84 \%$ bicarbonate solution) 


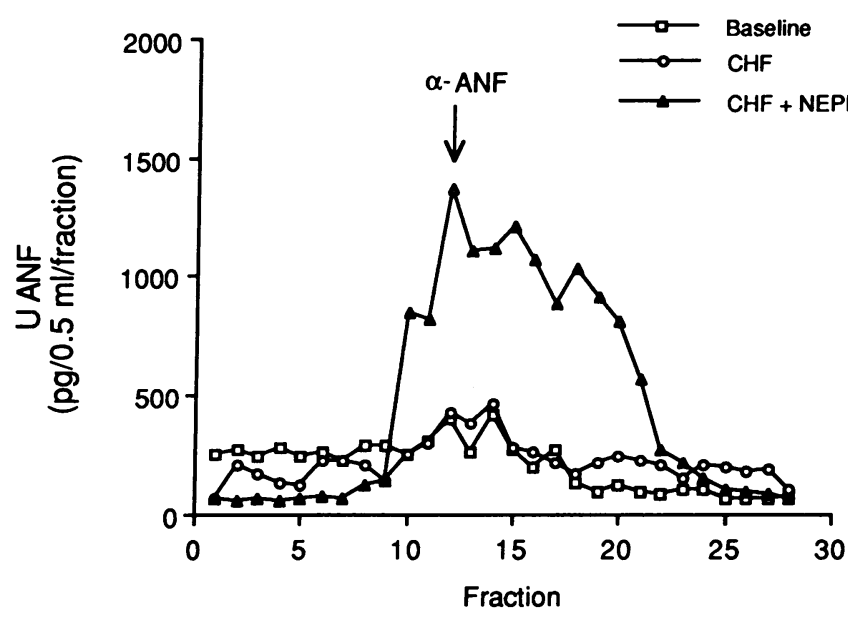

Figure 5. Characterization of urinary atrial natriuretic factor. Gel filtration chromatography of a representative urine sample at baseline, $\mathrm{CHF}$, and after administration of NEPI (60 mg/ $\mathrm{kg}$ i.v.).

across the lung, suggesting a significant role for NEP in the pulmonary degradation of ANF. Also, under normal physiologic conditions, $\mathrm{U}_{\mathrm{CL}} \mathrm{ANF}$ was significant. However, during $\mathrm{CHF}$, the $\mathrm{U}_{\mathrm{CL}} \mathrm{ANF}$ and FE ANF markedly decreased, consistent with enhanced urinary degradation of ANF. NEPI, in group II, prevented the decrease in $\mathrm{U}_{\mathrm{Cl}} \mathrm{ANF}$ and $\mathrm{FE}$ ANF during acute CHF. In addition to the alteration in pulmonary and urinary metabolism of ANF, NEPI produced cardiorenal responses independent of further increases in circulating plasma ANF concentrations in acute $\mathrm{CHF}$.

Since ANF is secreted by both the right and left atria, accurate assessment of pulmonary clearance of ANF requires measurement of ANF at a pulmonary venous site. Hollister and colleagues, upon sampling the gradient from the pulmonary artery to the pulmonary capillary wedge or pulmonary venous circulation, demonstrated a $24 \%$ extraction of ANF across the lung. This magnitude of extraction compared closely to in vitro analysis of the isolated perfused guinea pig lung by Weselcouch and colleagues (29). In this study, $P_{E X} A N F$ was significant at baseline in normal anesthetized dogs, and supports the concept that the lung is a major site of ANF metabolism. The role of the lung in the extraction of plasma ANF has been disputed by other studies (16-19), although differences in sampling sites and techniques may explain this discrepancy. Our study, in a paired design with homogenous $\mathrm{CHF}$, revealed that $\mathrm{P}_{\mathrm{CL}} \mathrm{ANF}$ tended to decrease with the onset of $\mathrm{CHF}$, although $\mathrm{P}_{\mathrm{EX}} \mathrm{ANF}$ was not altered. Previous studies have attempted to assess $P_{C L} A N F$ in patients with varying degrees of $\mathrm{CHF}$, however their results were not conclusive $(19,20)$.

There are several mechanisms which may mediate the $P_{E X} A N F$. These possible mechanisms include clearance receptor binding, tissue uptake, and protease degradation. NEP 24.11 has recently been shown to be present within the lung (21). Interestingly, pathophysiologic conditions that cause elevation of plasma ANF also produce elevated levels of NEP (30). To date, assessment of the $P_{E X} A N F$ in a clinical condition such as CHF, in the presence of NEPI 24.11, is lacking. This study reveals that NEPI administration during CHF abolishes the $P_{E X} A N F$. This does not rule out other possible mechanisms for the $P_{E X} A N F$, but suggests that protease degradation by NEP plays a significant role in $P_{E X} A N F$. Also, with this evidence of
NEP mediating $P_{E X} A N F$, the unaltered degree of pulmonary extraction in the setting of markedly elevated plasma ANF during CHF suggests a nonsaturable enzyme system, similar to that seen in the proximal tubule of the nephron (9).

While the lung may be an important site of NEP, the principle site of NEP is within the brush border of the proximal tubule. In vitro studies have demonstrated this enzyme functions in a nonsaturable fashion (9). Kenny and colleagues have proposed that proximal brush border NEP prevents biologically active ANF from reaching the terminal nephron, which is the nephron segment where ANF acts via a cGMP second messenger system to decrease sodium reabsorption (31).

This study also assessed $U_{C L} A N F$ in the presence and absence of acute CHF. Similar to the lung, the $U_{C L} A N F$ is signifcant at baseline. With the onset of acute $\mathrm{CHF}$, a marked decrease in $U_{C L} A N F$ was observed. This decrease in $U_{C L} A N F$ during $\mathrm{CHF}$, despite a marked elevation of plasma ANF and a maintenance of GFR, is consistent with the nonsaturable nature of NEP in vivo, as demonstrated by Berg et al. in vitro. In the presence of NEPI, the decrease in $U_{C L} A N F$ was not only prevented, but tended to increase. The increase in $U_{C L} A N F$ was associated with a significant diuresis and natriuresis in acute $\mathrm{CHF}$. This observation may suggest that enhanced renal degradation of endogenous ANF by NEP may contribute to the attenuated renal natriuretic action of ANF in CHF (23).

Previous studies have investigated NEPI in states characterized by elevated levels of plasma ANF (32-40). In these studies the cardiovascular actions of NEPI were attributed to increases in circulating ANF by inhibition of ANF degradation (33, 35$37,40)$. In the normal $\operatorname{dog}(22)$, NEPI (SQ 28,603) resulted in a decrease in CO and an increase in SVR, without a significant change in MAP. Despite a tendency for atrial pressures to decrease, plasma ANF increased. This increase in circulating ANF would suggest that decreases in ANF degradation contributed to the increased circulating ANF levels. In experimental chronic CHF (23), NEPI (SQ 28,603) produced a nonsignificant decline in $\mathrm{CO}$ and an increase in SVR, with no change in MAP. Atrial pressures tended to decrease while plasma ANF increased. Taken together, these observations support the concept that NEPI results in an increase of plasma ANF.

In this study, NEPI (SQ 28,603) maintained CO, SVR, and MAP during acute CHF. In contrast, during recovery, NEPI was associated with decreases in cardiac filling pressures and $\mathrm{CO}$, consistent with a decrease in cardiac preload. Moreover, in the NEPI group, plasma ANF did not increase further, even with the prevention of $P_{E X} A N F$. This failure of plasma ANF to increase may be due to the decrease in atrial pressures, though modest, which may decrease the stimulus for endogenous ANF secretion. Also, with the administration of NEPI the $U_{C L} A N F$ increased, possibly contributing to the lack of increase in plasma ANF.

In previous studies, the renal response to NEPI, in dogs with and without chronic $\mathrm{CHF}$, was characterized by a signifcant diuresis and natriuresis without increases in GFR or RBF $(22,23)$. Similarly, in this study during acute CHF, NEPI resulted in a diuresis and natriuresis. An increase in GFR, not noted in chronic CHF or normal circumstances $(22,23)$, would suggest that renal hemodynamic responses contribute to the natriuretic effects of NEPI in acute CHF.

Previous studies have established cGMP as the biologic second messenger of ANF (41-45). In this study, plasma cGMP 
increased significantly during acute $\mathrm{CHF}$, in association with a marked elevation in plasma ANF. Interestingly, plasma cGMP increased further after NEPI, and remained elevated during the recovery period. This further elevation of plasma cGMP in response to NEPI occurred without a further elevation of plasma ANF. One possible mechanism for this plasma cGMP response is an effect of NEPI to promote the local action of ANF.

The biologic marker for the renal action of ANF, urinary cGMP $(41,43)$, was also assessed in this study. Associated with these changes in urinary cGMP, we also assessed immunoreactive urinary ANF as determined by both RIA and gel filtration chromatography (GFC). In contrast to plasma cGMP, $\mathrm{U}_{\mathrm{CGMP}} \mathrm{V}$, as well as urinary immunoreactive ANF by RIA and GFC, did not increase with the onset of CHF, consistent, in part, with the tubular degradation of urinary ANF. However after NEPI, $U_{\mathrm{cGMP}} \mathrm{V}$ increased markedly and remained elevated during the recovery period from NEPI. Similarly, the $\mathrm{U}_{\mathrm{CL}} \mathrm{cGMP}$ increased significantly after NEPI. The acute $\mathrm{U}_{\text {CGMP }} \mathrm{V}$ response to NEPI importantly paralleled urinary sodium excretion, suggesting that delivery of ANF to the terminal nephron may activate cGMP and contribute to the natriuretic response. Supporting such a speculation is the increase in urinary ANF by RIA and GFC following NEPI, and the recent studies by Sonnenberg et al. demonstrating a luminal action of ANF in the inner medullary collecting duct to promote natriuresis (46). One must however be cautious in interpreting this increase in urinary ANF despite the increases in both urinary cGMP and sodium, as this assay technique may detect open-ringed peptide. Other mechanisms such as increased GFR after NEPI, may also be considered as contributing to the renal response. While the urinary excretion of ANF and cGMP remained elevated during the recovery period, urinary excretion of sodium declined. This phenomena may best be explained by the decrease in MAP and renal perfusion pressure during the recovery period (47).

The NEPI employed in this experiment, SQ 28,603 , has minimal activity against other brush border enzymes, such as angiotensin converting enzyme and aminopeptidase $M$. However, the activity of SQ 28,603 upon peptidases outside the brush border of the nephron is not known. NEP has been shown, via in vitro analysis, to hydrolyze other factors such as kinins $(48,49)$. Because the influence of NEPI on these other factors was not assessed in this study, we can not exclude their contribution to the observed hemodynamic and renal responses, although studies using a monoclonal antibody to ANF in rats with $\mathrm{CHF}(50)$ have suggested that potentiation of ANF activity is a major contributor to the observed renal responses of NEPI.

In summary, these studies demonstrate a significant clearance of plasma ANF across the pulmonary circulation under normal physiologic conditions. Although the $P_{C L} A N F$ tended to decrease during acute $\mathrm{CHF}$, the $\mathrm{P}_{\mathrm{EX}} \mathrm{ANF}$ was not altered. The administration of NEPI during acute CHF abolished both the clearance and the extraction of plasma ANF across the lung, supporting a significant role for NEP in the pulmonary degradation of ANF. Analogously, we observed a significant $\mathrm{U}_{\mathrm{CL}} \mathrm{ANF}$ under normal physiologic conditions. In CHF, marked decreases in $\mathrm{U}_{\mathrm{CL}} \mathrm{ANF}$ and $\mathrm{FE}$ ANF were observed, consistent with enhanced urinary degradation of the peptide.
These decreases in $\mathrm{U}_{\mathrm{CL}} \mathrm{ANF}$ and $\mathrm{FE}$ ANF, despite the marked increases of plasma ANF during acute $\mathrm{CHF}$, suggest the nonsaturability of NEP within the kidney in vivo. NEPI prevented the decreases in $U_{C L} A N F$ and $F E A N F$, and enhanced the renal response to endogenous $A N F$, independent of further increases in circulating plasma ANF concentrations during acute $\mathrm{CHF}$. These enhanced renal responses and observed effects upon cardiac hemodynamics may be mediated by the potentiation of endogenous ANF as manifested by increases in urinary and plasma cGMP. These studies importantly support a role for NEP in the in vivo metabolism of endogenous ANF during CHF. These studies also support a role for NEPI in potentiating the actions of endogenous ANF in acute CHF.

\section{Acknowledgments}

The authors gratefully acknowledge the Bristol-Myers-Squibb Institute for Medical Research (Princeton, NJ) for supplying SQ 28,603, and the assistance of Andrea A. Seymour, Ph.D., Norma G. Delaney, Ph.D., and Nick Trippodo, Ph.D. The authors also wish to thank Pai Kao, Ph.D. of Mayo Clinic and Foundation (Rochester, MN) for his expert assistance.

This research was supported by grants from the National Institutes of Health (NIH) HL-36634, the Mayo Foundation, and the National Kidney Foundation of the Upper Midwest. Dr. Perrella was supported by the NIH Multidisciplinary Training Grant in Hypertension HL07269, and Dr. Margulies was supported by the NIH Training Grant in Cardiovascular Research HL-07111-14. Dr. Burnett is an Established Investigator of the American Heart Association.

\section{References}

1. Edwards, B. S., R. S. Zimmerman, T. R. Schwab, D. M. Heublein, and J. C. Burnett, Jr. 1988. Atrial stretch, not pressure, is the principle determinant controlling the acute release of atrial natriuretic factor. Circ. Res. 62:191-195.

2. Ledsome, J. R., N. Wilson, C. A. Cournaga, and A. J. Rankin. 1985. Release of atrial natriuretic peptide by atrial distention. Can. J. Physiol. 63:739742 .

3. Burnett, J. C., Jr., J. P. Granger, and T. J. Opgenorth. 1984. Effects of synthetic atrial natriuretic factor on renal function and renin release. $\mathrm{Am}$. J. Physiol. 247:F862-F866.

4. Miller, W. L., B. S. Edwards, R. S. Zimmerman, and J. C. Burnett, Jr. 1990 Renal-endocrine adaptation to endogenous atrial natriuretic factor during tachycardia-induced reductions in renal perfusion pressure. Circ. Res. 66:76-83.

5. Burnett, J. C., Jr., P. C. Kao, D. C. Hu, D. W. Heser, D. M. Heublein, J. P. Granger, T. J. Opgenorth, and G. S. Reeder. 1986. Atrial natriuretic peptide elevation in congestive heart failure in the human. Science (Wash. DC). 231:1145-1147.

6. Scriven, T. A., and J. C. Burnett, Jr. 1985. Effects of synthetic atrial natriuretic peptide on renal function and renin release in acute experimental heart failure. Circulation. 72:892-897.

7. Zimmerman, R. S., J. A. Schirger, B. S. Edwards, T. R. Schwab, D. M. Heublein, and J. C. Burnett, Jr. 1987. Cardio-renal-endocrine dynamics during stepwise infusion of physiologic and pharmacologic concentrations of atrial natriuretic factor in the dog. Circ. Res. 61:662-669.

8. Maack, T., M. Suzuki, F. A. Almeida, D. Nussenzveig, R. M. Scarborough, G. A. McEnroe, and J. A. Lewicki. 1987. Physiological role of silent receptors of atrial natriuretic factor. Science (Wash. DC). 238:675-678.

9. Berg, J. A., M. Hayashi, Y. Fujii, and A. I. Katz. 1988. Renal metabolism of atrial natriuretic peptide in the rat. Am. J. Physiol. 255:F466-F473.

10. Stephenson, S. L., and A. J. Kenny. 1987. The hydrolysis of å-human atrial natriuretic peptide by pig kidney microvillar membranes is initiated by endopeptidase 24.11. Biochem. J. 243:183-187.

11. Sonnenberg, J. L., Y. Sakane, A. Y. Jeng, J. A. Koehn, J. A. Ansell, L. P. Wennogle, and R. D. Ghai. 1988. Identification of protease 3.4.24.11 as the major atrial natriuretic factor degrading enzyme in the rat kidney. Peptides. 9:173-180. 
12. Olins, G. M., P. A. Krieter, A. J. Trapani, K. L. Spear, and P. R. Bovy. 1989. Specific inhibitors of endopeptidase 24.11 inhibit the metabolism of atria natriuretic peptides in vitro and in vivo. Mol. Cell. Endocrinol. 61:201-208.

13. Woods, R. L. 1988. Contribution of the kidney to metabolic clearance of atrial natriuretic peptide. Am. J. Physiol. 255:E934-E941.

14. Condra, C. L., E. A. Leidy, P. Bunting, C. C. Colton, R. F. Nutt, M Rosenblatt, and J. W. Jacobs. 1988. Clearance and early hydrolysis of atrial natriuretic factor in vivo. J. Clin. Invest. 81:1348-1354.

15. Tonolo, G., M. McMillan, J. Polonia, A. Pazzola, P. Montorsi, A. Soro, N. Glorioso, and M. A. Richards. 1988. Plasma clearance and effects of å-hANP infused in patients with end-stage renal failure. Am. J. Physiol. 254:F895-F899.

16. Crozier, I. G., M. G. Nicholls, H. Ikram, E. A. Espiner, T. G. Yandle, and S. Jans. 1986. Atrial natriuretic peptide in humans, production and clearance by various tissues. Hypertension. 8(Suppl. II):II-1-II-15.

17. Espiner, E. A., M. G. Nicholls, T. G. Yandle, I. G. Crozier, R. C. Cuneo, D. McCormick, and H. Ikram. 1986. Studies on the secretion, metabolism, and action of atrial natriuretic peptide in man. J. Hypertens. (Suppl. II):S85-S91.

18. Schutten, H. J., J. H. Henriksen, and J. Warberg. 1987. Organ extraction of atrial natriuretic peptide (ANP) in man. Significance of sampling site. Clin. Physiol. 7:125-132.

19. Richards, A. M., J. G. Cleland, G. Tonolo, G. D. McIntyre, B. J. Leckie H. J. Dargie, S. G. Ball, and J. I. S. Robertson. 1986. Plasma å-natriuretic peptide in cardiac impairment. Br. Med. J. 293:409-412.

20. Hollister, A S., R. J. Rodeheffer, F. J. White, J. R. Potts, T. Imada and T. Inagami. 1989. Clearance of atrial natriuretic factor by lung, liver, and kidney in human subjects and the dog. J. Clin. Invest. 83:623-628.

21. Erdös, E. G., and R. A. Skidgel. 1989. Neutral endopeptidase 24.11 (enkephalinase) and related regulators of peptide hormones. FASEB J. 3:145-151.

22. Margulies, K. B., P. G. Cavero, A. A. Seymour, N. G. Delaney, and J. C. Burnett, Jr. 1990. Neutral endopeptidase inhibition potentiates the renal actions of atrial natriuretic factor. Kidney Int. 38:67-72.

23. Cavero, P. G., K. B. Margulies, J. Winaver, A. A. Seymour, N. G. Delaney, and J. C. Burnett, Jr. 1990. Cardiorenal actions of neutral endopeptidase inhibition in experimental congestive heart failure. Circulation. 82:196-201.

24. Redfield, M. M., B. S. Edwards, M. D. McGoon, D. M. Heublein, L. L. Aarhus, and J. C. Burnett, Jr. 1989. Failure of atrial natriuretic factor to increase with volume expansion in acute and chronic congestive heart failure in the dog. Circulation. 80:651-657.

25. Führ, J., J. Kaczmarczyk, and C. J. Kr̈uttgen. 1955. Eine einfache colorimetrische methode zur inulinbestimmung fur Nierenclearanceuntersuchungen bei Stoffwechselgesunden und Diabetikern. Klin. Wochenschr. 33:729-730.

26. Steiner, A. L., C. W. Parker, and D. M. Kipnis. 1972. Radioimmunoassay for cyclic nucleotides. I. Preparation of antibodies and iodinated cyclic nucleotides. J. Biol. Chem. 247:1106-1113.

27. Marumo, F., H. Sakamoto, K. Ando, T. Ishigami, and M. Kawakami. 1986. A highly sensitive radioimmunoassay of atrial natriuretic peptide (ANP) in human plasma and urine. Biochem. Biophys. Res. Commun. 137:231-236.

28. Wei, C.-M., P. Kao, D. Heublein, and J. C. Burnett, Jr. 1990. Beta-atria natriuretic factor presence in humans with congestive heart failure. Clin. Res. 38:828a. (Abstr.)

29. Weselcouch, E. O., W. R. Humphrey, and J. W. Aiken. 1985. Effect of pulmonary and renal circulations on activity of atrial natriuretic factor. Am. J. Physiol. 249:R595-R602.

30. Johnson, A. R., J. J. Coalson, J. Ashton, M. Larumbide, and E. G. Ervin. 1985. Neutral endopeptidase in serum samples from patients with adult respiratory distress syndrome. Am. Rev. Respir. Dis. 132:1262-1267.

31. Kenny, A. J., and S. L. Stephenson. 1988. Role of endopeptidase-24.11 in the inactivation of atrial natriuretic peptide. FEBS Lett. 232:1-8.

32. Trapani, A. J., G. J. Smits, D. E. McGraw, K. L. Spear, J. P. Koepke,
G. M. Olins, and E. H. Blaine. 1988. Effect of thiorphan on the depressor and natriuretic action of atrial peptides. FASEB J. 2:936a. (Abstr.)

33. Fennell, S. A., J. N. Swerdel, N. G. Delaney, and A. A. Seymour. 1988 Potentiation of the renal and depressor responses to ANP 99-126 by SQ 29,072 in conscious dogs. FASEB J. 2:936a. (Abstr.)

34. Zimmerman, M. B., C. M. McMartin, G. Yazay, L. P. Wennogle, and R. L. Webb. 1988. Degradation of atrial natriuretic peptide: Pharmacologic effects of protease ED 24.11 inhibition. FASEB J. 2:A937. (Abstr.)

35. Koepke, J. P., L. D. Tyler, A. J. Trapani, P. R. Bovy, K. L. Spear, G. M. Olins, and E. H. Blaine. 1989. Interaction of non-guanylate cyclase-linked atriopeptin receptor ligand and endopeptidase inhibitor in conscious rats. J. Pharmacol. Exp. Ther. 249:172-176.

36. Northridge, D. B., C. T. Alabaster, J. M. C. Connell, S. G. Dilly, A. F Lever, A. G. Jardine, P. L. Barclay, H. J. Dargie, I. N. Findlay, and G. M. R. Samuels. 1989. Effects of UK 69 578; a novel atriopeptidase inhibitor. Lancet. ii:591-593.

37. Samuels, G. M. R., P. L. Barclay, C. J. Peters, and P. Ellis. 1989. Atriopeptidase inhibitors, a novel class of drug that raises levels of endogenous atria natriuretic factor-the preclinical pharmacology of UK-69,578. J. Am. Coll. Card. 13:75a. (Abstr.)

38. Alabaster, C. T. I Machin, P. L. Barclay, and G. M. R. Samuels. 1989. The effect of UK 69,678 , an atriopeptidase inhibitor, in a conscious dog model of cardiac insufficiency. J. Am. Coll. Card. 13:75a. (Abstr.)

39. Jardine, A. G., J. M. C. Connell, D. B. Northridge, S. Dilly, B. Leckie, and A. F. Lever. 1989. Renal effects of the atriopeptidase inhibitor UK 69,578 in normal man. Am. J. Hypertens. 2:1307a. (Abstr.)

40. Seymour, A. A., S. A. Fennell, and J. N. Swerdel. 1989. Potentiation of renal effects of atrial natriuretic factor-(99-126) by SQ 29,071. Hypertension. 14:87-97.

41. Hamet, P., J. Tremblay, S. C. Pang, R. Skuherska, E. L. Schiffrin, R. Garcia, M. Cantin, J. Genest, R. Palmour, F. R. Ervin, S. Martin, and R. Goldwater. 1986. Cyclic GMP as mediator and biological marker of atrial natriuretic factor. J. Hypertens. 4(Suppl.):S49-S56.

42. Murad, F., R. M. Rapoport, and R. Fiscus. 1985. Role of cyclic-GMP in relaxations of vascular smooth muscle. J. Cardiovasc. Pharmicol. 7(Suppl.):S111-S118.

43. Wong, K. R., M. H. Xie, L. B. Shi, F. Y. Liu, C. L. Huang, D. G. Gardner, and M. G. Cogan. 1988. Urinary CGMP as biological marker of the renal activity of atrial natriuretic factor. Am. J. Physiol. 255:F1220-F1224.

44. Nonoguchi, H., M. A. Knepper, and V. C. Manganiello. 1987. Effects of atrial natriuretic factor on cyclic guanosine monophosphate and cyclic adenosine monophosphate accumulation in microdissected nephron segments from rats. $J$. Clin. Invest. 79:500-507.

45. Nonoguchi, H., J. M. Sands, and M. A. Knepper. 1988. Atrial natriuretic factor inhibits vasopressin-stimulated osmotic vater permeability in rat inner medullary collecting duct. J. Clin. Invest. 82:1383-1390.

46. Sonnenberg, H., U. Honrath, and D. R. Wilson. 1990. In vivo microperfusion of inner medullary collecting duct in rats: effects of amiloride and ANF. Am. J. Physiol. 259:F222-F226.

47. Redfield, M. M., B. S. Edwards, D. M. Heublein, and J. C. Burnett, Jr. 1989. Restoration of the renal response to atrial natriuretic factor in experimental low output heart failure. Am. J. Physiol. 257:R917-R923.

48. Ura, N., O. A. Carretero, and E. G. Erd̈os. 1987. Role of renal endopeptidase 24.11 in kinin metabolism in vitro and in vivo. Kidney Int. 32:507-513.

49. Shimamori, Y., T. Watanabe, and Y. Fujimoto. 1986. Specificity of a membrane-bound neutral endopeptidase from rat kidney. Chem. Pharm. Bull. 34:275-280.

50. Wilkins, M. R., S. L. Settle, P. T. Stockmann, and P. Needleman. 1990 Maximizing the natriuretic effect of endogenous atriopeptin in a rat modes of heart failure. Proc. Natl. Acad. Sci. USA. 87:6465-6469. 